\title{
A gestão profissional e a natureza de uma universidade católica
}

\author{
The professional management and the nature of a catholic university
}

\section{La gestión profesional y la naturaleza de una universidad católica}

\author{
Lúcio Gomes Dantas ${ }^{1}$ \\ Universidade Católica de Brasília, Reitoria e Programa de Pós-graduação em Educação, \\ Assessor de Desenuoluimento Institucional e Professor colaborador \\ https://orcid.org/0000-0002-5630-5060
}

Maria Regina Carualho Teixeira de Oliveira²

Equipe Consultoria, Diretora-presidente

https://orcid.org/0000-0003-2368-0435

Resumo: Nos últimos anos, a mercantilização da Educação Superior brasileira e as estratégias de mercado das instituições lucrativas têm solapado as Instituições de Ensino Superior (IES). 0 impacto da operacionalização dos serviços educacionais disponibilizados à sociedade tem apresentado aspectos que reverberam na gestão profissional, sobretudo nas universidades católicas. Diante disso, os imperativos mercadológicos têm afetado, sobremaneira, a missão e os valores das IES católicas. Nesse sentido, essa comunicação reflete aspectos constitutivos da gestão profissional e o impacto deles na identidade da universidade católica. Para realizar este estudo, utilizou-se o método qualitativo, de caráter exploratório, escrito sob a perspectiva de um ensaio teórico, no qual se realiza uma discussão conceitual sobre o modelo de gestão profissional que atende ao mercado atual de Educação Superior. Utilizaram-se, ainda, documentos de uma universidade católica, bem como de sua mantenedora, para fazer interface com as concepções de gestões vigentes no cenário atual das IES. Discutiram-se as concepções que permeiam a gestão, a missão e os valores institucionais perante as demandas do atual mercado educacional superior. Observou-se que, na discussão dos autores, critica-se a forma de gerir sob a perspectiva do mercado neoliberal e que seu principal impacto na Educação Superior pode desqualificar a identidade da universidade católica. Conclui-se que é importante preservar a identidade desse tipo de universidade, uma vez que se leva em conta a comunidade de estudiosos que se dedica à investigação, ao ensino e às várias formas de serviço à comunidade como promoção dos saberes e missão cultural.

Palavras-chave: Gestão educacional. Universidade católica. Identidade. Mercado educacional.

Doutor em Educação pela Universidade de Brasilia (UnB).

Doutora e Mestra em Administração pela Universidade Federal de Minas Gerais (UFMG). 
Abstract: In recent years, the commodification of Brazilian higher education and the market strategies of profitable institutions have undermined Higher Education Institutions (HEls). The impact of the operationalization of educational services, made available to society, has presented aspects that have reverberated in professional management, especially in catholic universities. Faced with this, market imperatives have greatly affected the mission and values of catholic HEls. In this sense, this communication reflects constitutive aspects of professional management and their impact on the identity of a catholic university. To perform this study it was used the qualitative method, of exploratory nature, written from the perspective of a theoretical essay, in which a conceptual discussion is held on the model of professional management that serves the current market of higher education. It was also used documents from a catholic university, as well as from its maintainer, to interface with the conceptions of management in force in the current scenario of HEls. It was discussed the conceptions that permeate the management, the mission and the institutional values facing the demands of the current higher education market. It was observed that, in the discussion of the authors, it is criticized the way to manage from the perspective of the neoliberal market and that its main impact on Higher Education can disqualify the identity of the catholic university. It is concluded that it is important to preserve the identity of this type of university, since it takes into account the community of scholars that is dedicated to research, teaching and various forms of service to the community as promotion of knowledge and cultural mission.

Keywords: Educational management. Catholic university. Identity. Educational market.

Resumen: En los últimos años, la comercialización de la educación superior brasileña y las estrategias de mercado de las instituciones lucrativas han debilitado a las instituciones de educación superior (IES). El impacto de la operacionalización de los servicios educativos, puestos a disposición de la sociedad, ha presentado aspectos que repercuten en la gestión profesional, especialmente en las universidades católicas. Ante esto, los imperativos del mercado han afectado enormemente la misión y los valores de las IES católicas. En este sentido, esta comunicación refleja aspectos constitutivos de la gestión profesional y su impacto en la identidad de la universidad católica. Para llevar a cabo este estudio, se utilizó el método cualitativo, de carácter exploratorio, escrito desde la perspectiva de un ensayo teórico, en el que se realiza una discusión conceptual sobre el modelo de gestión profesional que cumpla con el mercado actual de educación superior. También se utilizaron documentos de una universidad católica, así como de su mantenedora, para interactuar con las concepciones de gestión vigentes en el escenario actual de las IES. Se discutieron las concepciones que impregnan la gestión, la misión y los valores institucionales enfrente a las demandas del mercado educativo superior actual. Se observó que, en la discusión de los autores, se critica la forma de gestionar desde la perspectiva del mercado neoliberal y que su principal impacto en la educación superior puede descalificar la identidad de la universidad católica. Se concluye que es importante preservar la identidad de este tipo de universidad, una vez que tiene en cuenta 
la comunidad de académicos que se dedican a la investigación, a la enseñanza y a las diversas formas de servicio a la comunidad como promoción de los conocimientos y misión cultural.

Palabras clave: Gestión educativa. Universidad católica. Identidad. Mercado educativo.

Recebido em 28 de outubro de 2019

Aceito em 16 de abril de 2020

Publicado em 17 de agosto de 2020

\section{INTRODUÇÃO}

A educação é um meio de aprimoramento humano que se fundamenta na promoção da pessoa, em vista da atuação transformadora que possui na sociedade. Nessa lógica, a interação científico-acadêmica com o conhecimento humano revela que uma universidade católica se torna uma comunidade de estudiosos que representa vários saberes humanos. Dessa forma, esse tipo de instituição se dedica à investigação, ao ensino e às várias formas de serviço correspondentes à sua função social, além de inspirar e realizar sua investigação, o ensino e todas as outras atividades, segundo os ideais e os princípios que humanizam a sociedade.

Sabemos que aspectos da mercantilização adentraram na esfera da Educação Superior brasileira, uma vez que se vincularam às estratégias de mercado das instituições lucrativas e se somaram às exigências de qualidade por parte da sociedade e dos organismos reguladores da Educação Superior. Vale salientar que, de acordo com Jezine et al. (2010, p. 277), esses mesmos organismos que comandam a lógica mercantil, sob a égide da globalização, ditam políticas para a Educação Superior e fazem com que "o Estado priorize a aplicação do fundo público nos interesses do capital", sobretudo quando se reduz sua ação social empreendedora, tornando-se estritamente agentes regulatórios de políticas sociais. Por conseguinte, essas políticas, nas mãos privatistas, configuram-se em "internacionalização como bens de mercado".

Ainda no tocante à Educação Superior, esse pensamento ratifica estudos de Zamagni (2013, p. 6) quando este critica a influência do mercado nas universidades, pois, sob essa ótica, "a universidade tem de estar estruturalmente organizada, de modo a aumentar o grau de empregabilidade dos estudantes, o que significa que ela deve se organizar levando em consideração as necessidades do mundo dos negócios."

Ante o exposto, não podemos esquecer que vivemos em uma sociedade cada vez mais caracterizada pela racionalidade técnica, sucumbindo a valores essencialmente 
humanistas. Dessa forma, a universidade tem a oportunidade de ser uma instituição privilegiada de aprendizagens e educação, como um lugar bom para se trabalhar e viver.

A universidade, ao assumir o papel de organização formal, pode condicionar as pessoas a se tornarem demasiadamente burocráticas, impessoais e técnicas. Com esse tipo de visão, a universidade tende a tratar os seus estudantes como meros clientes que têm interesses a serem atendidos e problemas a serem resolvidos. Entretanto, esses aspectos não coadunam com a operacionalização da qualidade nos serviços educacionais disponibilizados à sociedade por uma instituição confessional e, em especial, católica.

Neste ensaio queremos especificar a universidade católica por entender que a investigação científica e o saber giram em torno dos valores cristãos, baseados, sobretudo, nos Evangelhos. Com isso, não basta reduzir seus princípios fundamentais entre ensino, pesquisa e extensão, pois as relações entre ciência, tecnologia, inovação e desenvolvimento são interativas, simultâneas e têm as pessoas como principal força da instituição.

Em nossa sociedade, com tantas desigualdades sociais e com altos índices de pessoas abaixo da linha de pobreza, uma universidade católica deve se colocar a serviço do conhecimento dessa realidade de pauperização e de injustiças sociais, propondo projetos arrojados para as instâncias responsáveis à sua execução. Ela tende a ser, na comunidade, um espaço de defesa da justiça, na proposição de ações de solidariedade e no fortalecimento dos mecanismos de transformação das realidades de indigências. Uma comunidade educativa católica não se fecha no interior de seus muros; ela enfrenta os desafios nos tempos atuais, não devendo se dobrar diante dos apelos mercadológicos, muitas vezes predatórios, pois sob o seu jugo está a força integradora para a transformação social.

Para acompanhar e colocar em prática essas ações fundamentais é importante o papel de gestores líderes, uma vez que devem possuir alta performance gerencial para gerir processos que coadunem com a missão ou natureza de uma instituição católica. Nesse sentido, compartilhamos da mesma opinião de Wahlbrinck e Pacheco (2017, p. 65), quando afirmam que "a universidade é, por excelência, instituição em que se dá a formação de liderança que, em sua atuação profissional, serão sujeitos comprometidos com a transformação daquilo que não contribui para a dignidade da vida." Com isso, aspectos de liderança e de aprendizagem colaborativa são fontes inestimáveis de criatividade para gerar novos conhecimentos e novas oportunidades.

Consideramos que uma gestão qualificada coloca o gestor em uma posição para estimular os talentos, gerando mais autonomia de trabalho, evitando gargalos e engessamentos burocráticos. Além disso, um gestor que qualifica a sua comunidade à luz do conhecimento gerado na universidade leva a impactos qualitativos na sociedade como 
um todo. Nesse sentido, observamos os sempre atuais apontamentos de Drucker (2017) a respeito do gestor dentro do pensamento gerencial mais eficaz e pela liderança mais ética.

Assim, o escopo deste estudo se define sob a problemática que emerge da gestão profissional em uma instituição universitária católica, em que pretendemos refletir aspectos constitutivos da gestão profissional, sob a perspectiva do mercado educacional e de suas implicações com a identidade e a missão de uma universidade católica.

\section{AS ESCOLHAS METODOLÓGICA E EPISTEMOLÓGIICA}

Este estudo se caracteriza como de natureza predominantemente qualitativa pelo fato de nos permitir a interpretação dos fenômenos estudados e atribuir significados ao nosso objeto de estudo (FLICK, 2009). Fizemos a opção por um ensaio teórico, no qual se realiza uma discussão conceitual sobre o modelo de gestão profissional que atende à Educação Superior diante da identidade de uma universidade católica.

Como pressuposto, este ensaio prima pela diversificação de autores com o intuito de iluminar e permitir melhor ordenação e compreensão da realidade. Compreendemos, ainda, que esse tipo de investigação de processos se insere em determinados contextos. Além disso, preocupou-nos saber o que se tinha estudado sobre o problema que examinamos para evitar, consequentemente, uma réplica de trabalhos já realizados (MINAYO, 2010; RICHARDSON, 2017).

Discutimos a teoria baseada em pesquisa bibliográfica, como fundamento da abordagem qualitativa, com a finalidade de aprendizagem, aquisição e produção de conhecimento, ao chancelarmos um espaço preparatório para o desenvolvimento de trabalhos posteriores. Ressaltamos que todo o processo deste estudo teve a preocupação de contribuir para o pensamento crítico, bem como permitir ao leitor um novo olhar sobre o fenômeno estudado.

Nesse sentido, epistemologicamente, este ensaio busca abranger estudos clássicos sobre administração e gestão, por meio de autores, como Fayol (1990), Dias (2001), Donkin (2003), Drucker (2017), Morgan (2006) e Taylor (2009), bem como outros atuais, a exemplo de Carvalho (2013), Gaulejac (2007), Laval (2019), Lopes e Baldi (2009), Magaldi e Salibi Neto (2018). Quanto às reflexões sobre a universidade ou a Educação Superior nos baseamos em importantes trabalhos realizados por Audy (2017), Castanho (2002), Giroux (2010), Spring (2018) e Teodoro (2010). Sobre os temas de identidade e natureza da Educação Superior católica, tomamos como base os documentos papais de João Paulo II (1990) e de Francisco (2018a, 
2018b), da Conferência Nacional dos Bispos do Brasil (2019), de Zamagni (2013), da União de Educação Corporativa ${ }^{3}$ (2016, 2017) e da Universidade Comunitária Regional (2018).

Vale salientar que esse arcabouço literário reforça as ideias de Marconi e Lakatos (2013, p. 44), ao afirmarem que a finalidade da pesquisa bibliográfica é a de "colocar o pesquisador em contato direto com tudo aquilo que foi escrito sobre determinado assunto." Portanto, com essa literatura montamos um conjunto de ideias produzidas como base teórica para os principais conceitos deste estudo. Sabemos que a literatura de determinado assunto permite uma familiarização relevante, por proporcionar sensibilidade às "nuances sutis" da investigação (FLICK, 2009).

Acreditamos que a decisão epistemológica no percurso deste trabalho, por confirmar descobertas anteriores ou ao mesmo tempo superar as descobertas para novas investigações, fornece estudos para o desenvolvimento de futuras pesquisas.

É importante destacar que a visão deste estudo, a respeito da pesquisa bibliográfica, vai ao encontro do que apresenta Severino (2007, p. 122), como sendo "aquela que se realiza a partir do registro disponivel, decorrente de pesquisas anteriores", utilizando dados ou categorias teóricas já trabalhadas. A revisão de literatura permite, dessa forma, estabelecer a importância do estudo e ser um suporte para comparar os resultados com outros resultados (CRESWELL, 2016). Dessa maneira, como o objeto de estudo requer dados dispersos, acreditamos que esse tipo de pesquisa ajuda na disposição de uma bibliografia adequada para o recorte teórico necessário.

\section{TEMPOS AGUERRIDOS NO MUNDO DO TRABALHO E EDUCAÇÃO SUPERIOR}

Uma nova moral nos tempos modernos, ou pós-modernos, flecha o mundo do trabalho: a valorização do trabalho produtivo como sinônimo de progresso. Acoplado a esse aspecto, há o fato da produção mecanizada, em que o trabalho é glorificado como essência de nossa sociedade. Mais do que um progresso, o trabalho significa a generalização de um projeto de controle social, em que a elite dita o "desejo" do mercado como necessidade universal dessa nova ordem social. 
Sob essa perspectiva, destacamos o trabalho de Spring (2018) a respeito da "economização da educação", na qual organismos internacionais, a exemplo da Organização para a Cooperação e Desenvolvimento Econômico (OCDE), comparam sistemas educacionais em vista da padronização global, sob a retórica de investimentos e desenvolvimento humano, o que, na verdade, camufla o real interesse de se atingir o crescimento econômico global. Nesse sentido, os rankings desempenham papéis de regulação no mercado e de difusão de modelos organizacionais. Estudos realizados por Teodoro, Santos e Costa Junior (2018, p. 176) explicitam as intencionalidades que alguns rankings internacionais e brasileiro fazem ao "orientar a procura de formação superior por parte das elites em direção aos cursos com maior empregabilidade" e disponibiliza, ainda, indicadores que sejam "úteis para o mercado de trabalho no recrutamento dos profissionais melhor qualificados." Essas intencionalidades, com certeza, legitimam a lógica mercantil da educação.

Enfatizamos sobre esse entendimento, o que os gestores da Mantenedora da UCR pensam sobre o mercado educacional: "cada empresa precisa se preparar para entrar numa corrida pelas melhores posições do mercado. E, no fim do percurso, vence quem obtém o melhor rendimento." (UNIÃO DE EDUCAÇÃO CORPORATIVA, 2016, p. 62). Ou seja, do ponto de vista financeiro, o rendimento é o mais significativo para a missão da Mantenedora.

Esse pensamento vai ao encontro do que Dejours (2005, p. 41) discorre sobre as organizações, em que o lucro das empresas passou a ter uma hegemonia em sua identidade, assim como o tema sobre organização, gestão e gerenciamento faz parte das "práticas discursivas do neoliberalismo." Sobre as facetas do neoliberalismo, mais do que uma teoria econômica, Teodoro (2010, p. 41) nos alerta como os dispositivos de "tecnologia de governo" e de "contorno político à educação" se movem como "técnicas calculadas que podem ser descontextualizadas de suas fontes originais e recontextualizadas na constelação de relações contingentes e mutuamente construtivas", ou seja, a força que a mobilidade do capital tem em se moldar aos contextos educacionais emergentes.

Vivemos um tempo em que a máquina e o virtual são anunciados como libertadores do esforço físico, analogamente aprisionando a subjetividade, a vontade e a liberdade. Controlam-se, dessa forma, o fazer e o ser da pessoa. Assim, reduzir as pessoas à esfera mecanicista passa a ser um imperativo de muitas corporações, tendo em vista que muitas gestões sujeitam seus funcionários a operarem "como máquinas: de maneira rotinizada, eficiente, confiável e previsível." (MORGAN, 2006, p. 24).

Na razão do mercado o que impera é o medo, que fragiliza o indivíduo que sabe que não possui vontade própria sobre o que e como produz. 0 poder de decisão já não the pertence, como não the pertence o fruto de seu trabalho, estando à deriva do mercado. No fundo, sob essa ótica, o que importa é o "gerenciamento" a serviço do capital (GAULEJAC, 2007). Ao que tudo indica, na qualidade de gestores educacionais, é importante se dar conta 
dessa lógica perversa de sofrimento que se propicia às pessoas que trabalham na Educação Superior e que isso pode trazer danos irreversíveis à qualidade das relações humanas.

Quando acessamos a teoria clássica e científica da administração (FAYOL, 1990; TAYLOR, 2009), na qual a administração é vista como uma organização racional do trabalho, notamos que há uma acusação às práticas rudimentares de administrar até então em voga no início do século XX. Entretanto, essa teoria vaticina novos processos de planejamento, organização, direção, coordenação e controle nas empresas. Além da ênfase que se coloca na estrutura da organização, cujo objetivo é o de buscar a maior produtividade do trabalho, com racionalidade do tempo, maior eficiência do trabalhador e da empresa. Entendemos, sob essa perspectiva, que o empregado se insere numa redoma em que tudo é planejado e controlado nos mínimos detalhes, tudo passa a ser funcional e mecanicamente pensado.

Nesse sentido, as IES podem vivenciar essa ideologia sutil da eficiência no mercado de ensino, contribuindo para o aumento das cifras que podem salvar o patrimônio institucional, "cujo preço é determinado pelo mercado com o intuito central de obter lucro em benefício de seus proprietários e acionistas." (CARVALHO, 2013, p. 763). Para a referida autora não é novidade, como consequência da globalização, a transformação do setor educacional como objeto de interesse do grande capital. A esse respeito, o Papa Francisco (FRANCISCO, 2018b) adverte que "uma globalização sem esperança nem visão está exposta ao condicionamento de interesses econômicos, muitas vezes distantes de uma concepção correta do bem comum, e com facilidade produz tensões sociais, conflitos econômicos e abusos de poder."

Muitas instituições educacionais do Segmento Superior se transformaram em unidades educacionais como fábricas de cérebros, com seus distintos departamentos funcionais, buscando uma rede de interligações em nome de uma administração participativa e de uma gestão mais eficiente. Como nos alerta Giroux (2010, p. 35), “o Ensino Superior não pode ser controlado pela riqueza, tendência essa que reforça a diferença de oportunidades para os estudantes com base em sua capacidade de pagamento."

No tocante a isso, Morgan (2006, p. 29) afirma que "as responsabilidades dos cargos se interligam de tal forma que se complementam um ao outro tão perfeitamente quanto possível e se inter-relacionam através de uma cadeia escalar de comando expressa através do dito clássico 'um homem, um chefe'." O que faz corroborar, ao que tudo indica, o processo de dominação por racionalização burocrática. Assim, uma nova racionalização burocrática, disfarçada de gestão corporativa-participativa, controlaria as ações das instituições. Ante o exposto, mostra-se interessante a ideia de burocracia que Dias (2001, p. 190) nos fornece, ao prescrever como um

Processo gradual que se apresenta nas organizações, mediante o qual as relações se formalizam, a hierarquia se institucionaliza, a improvisação 
diminui, o trabalho de cada um se especializa, são criadas normas escritas, procedimentos e rotinas, se procura submeter a todos os membros da organização às mesmas regras e regulamentos e esses membros separam seu domicilio do local de trabalho.

No mundo corporativo, inclusive na esfera universitária, constata-se a rotatividade de pessoal. As organizações vêm, gradativamente, assegurando essa "filosofia" explicada por atitudes, crenças e práticas. Por outro lado, a ideia de vários membros e uma só cabeça na instituição poderá levar a cabo uma forte divisão entre "nós" e "eles".

Analogamente, enquanto o empregado avança para uma situação sempre almejada de obter meios de reduzir a fadiga e o esforço no trabalho, vive a contradição de reduzir frentes de trabalhos em uma velocidade jamais vista. Dessa forma, a questão a saber é se a equipe gestora acompanha o processo de ordenamento necessário da vida, do trabalho e da apropriação de seus frutos.

As ações racionais, voltadas para o mercado competitivo, aceleraram as fusões e aquisições de grandes conglomerados educacionais. Demandam-se, com isso, mudanças radicais de liderança, pois as instituições de Educação Superior não podem mais retroceder aos sistemas gerenciais tradicionais, por muitos chamados de "caseiros" ou "domésticos". Com efeito, a égide de novas iniciativas dos novos gestores para arrebanhar cada vez mais clientes em vez de estudantes satisfaz o mercado, indo de encontro aos anseios das famílias.

Com isso queremos dizer que não podemos abandonar valores tradicionais de liderança, como honestidade, saber delegar, comunicação, confiança, compromisso, criatividade, intuição, entre outros, mas aliá-los à gestão atual, como dizem Magaldi e Salibi Neto (2018, p. 175): "à perspectiva tradicional uma nova visão que agregue" competências e habilidades para o líder. Esses autores desenham o líder do futuro com o perfil de criador, de grande sonhador do futuro, focado, tomador de riscos, conhecedor dos processos, centrado no cliente, questionador e conector de ideias e de pessoas.

Essa nova gestão pode estar associada ao que autores, como lsmail, Malone e Geest (2015), apontam como "organizações exponenciais". As organizações exponenciais são consideradas novas instituições empresariais que adotam, de forma diferente, a realização de negócios e observam rápido crescimento da empresa, em curto prazo, comparando-a com o mesmo segmento. Traz, ainda, característica da forma de gestão baseada na não linearidade, descentralização, transparência e inovação, o que para as tradicionais universidades católicas pode ferir a sua missão em detrimento da desierarquização da gestão.

Diante disso, parece-nos que a figura do gestor, crescentemente, deve "desenvolver determinado conjunto de objetivos, tais como maior rentabilidades ou crescimento organizacional." (MORGAN, 2006, p. 323). Talvez aqui mereça o apelo de não se ter a ilusão da 
lógica destrutiva da eliminação da força humana de trabalho educacional e a consequente destruição de instituições idôneas e tradicionais de Educação Superior.

Esse tipo de lógica dos neoliberais restauradores e seus aliados, pela opção de ficarem os bons, os qualificados, poderá não sobrar ninguém, nem a história. A inversão desse raciocínio custará mudanças de rumo e de foco, pois é tempo de se recorrer a uma nova ética, focar no que legitime as relações humanas saudáveis, eticamente pensada em novas instituições de Educação Superior católicas.

Como diz Donkin (2003, p. 370):

Precisaremos de nada menos do que uma nova ética. [...] Que se concentre nas necessidades sociais, não as do emprego, que podem ter sido esboçadas em uma descrição seca, mas as do trabalho que deve ser realizado para assegurarmos a manutenção de sociedade saudável.

Portanto, devemos produzir valores de uso socialmente necessários e não valores de troca para um mercado segmentado e excludente que, em nome de um empreendimento monumental, pode estar solapando as pessoas sem tempo e apenas as burocratizando e mecanizando.

A homogeneidade parece ser uma característica primordial dos impactos sociais desse intenso e rápido processo de ajuste das mantenedoras das $\mathbb{E}$ S católicas. A dinâmica de uma gestão cada vez mais agressiva se baseia em um paradigma do tipo de automação flexível, aparelhado por uma burocratização, acoplado à parafernália de tecnologia da informação, negando as reais necessidades dos colaboradores e dos desdobramentos de suas inter-relações. Dessa forma, nega-se novamente a comunicação, causando distorção comunicacional.

A dominação gerencialista que vem cada vez mais tomando conta das instituições de Educação Superior prega a adesão voluntária à sanção disciplinar, a mobilização à obrigatoriedade, a incitação à imposição, a gratificação à punição, a responsabilidade à vigilância, e sua força se enraíza em um sistema de valores que incentiva o bajulamento, acoplando o lugar da realização do sujeito em si, encobrindo a ética profissional diante de decisões estratégicas de alto impacto para a instituição.

Nessa linha de pensamento, o renomado pesquisador Dejours (2005, p. 63), estudioso em sofrimento psíquico nas organizações, alerta-nos para: 
usual como resultado da incompetência, da falta de seriedade, do desleixo, da falta de preparo, da má vontade, da incapacidade ou do erro humanos.

À luz do já exposto até aqui, encaminhamo-nos para uma crítica ao modelo organizacional de trabalho, estilo fordista ortodoxo, que automatiza a "linha de montagem" e faz acreditar que estamos realizando um tipo de gestão participativa que visa ajustes de acordo com as flutuações do mercado. Dessa maneira, muitas mantenedoras de IES católicas têm rompido com os velhos paradigmas de gestão e se tornaram abertas às novas formas de gerir no mercado de Educação Superior.

Do mesmo modo, a imprevisibilidade, outro ponto marcante no mundo corporativo, traz os riscos que foram construidos, em parte, pelo impacto da ciência e da tecnologia, para as gerações que não viveram a era da empregabilidade e da estabilidade de emprego. 0 impacto da economia neoliberal acabou por criar cenários de riscos, dos quais não se tem experiências anteriores que orientem sobre o que fazer diante deles, salvo exceção, - raciocínio dos mega-administradores. Uma reversão ao passado parece inconcebível; - labor daqueles não engendraria na nova mecanização da esfera humana, pois a nova profissionalização para o mercado poderá exterminar um tipo de profissional que desejava ter relações pautadas no convivio humano e que almejava ser feliz pelo trabalho que exercia.

Sobre a instabilidade no emprego, Morgan (2006, p. 303) nos inquire de "como alguém pode sentir-se pertencendo a um time, sem ter a certeza de estar empregado na próxima semana?" A imprevisibilidade torna-se, assim, uma tônica no dia a dia do empregado, gerando desconfiança e insegurança. De acordo com Sennet (2009, p. 140), o desafio é o de organizar a vida dos trabalhadores, agora, num "capitalismo que nos deixa à deriva."

Sem dúvida, o fator econômico é hegemônico para definir quem se afilia à sociedade, sobretudo quando o indivíduo perde a sua renda ou salário e se torna "desfiliado", termo utilizado por Castel (2010) para traduzir situações nas quais as pessoas deixam de pertencer ou de estar vinculadas ao trabalho ou às redes mais amplas. 0 "desfiliado" tornase isolado, atomizado e desestimulado. Desse ponto de vista, Castel (2010, p. 569) reconhece que essas pessoas foram desligadas da sociedade. Ao ser desfiliada, a pessoa passa a viver da forma mais elementar neste mundo, por meio de sobrevivência e da "caridade" de outrem, tornando-se indigna, do ponto de vista do desenvolvimento humano.

Sobre isso, apresentam-se interessantes as distinções que Arendt (1991) nos traz ao afirmar que o labor e não o trabalho é a atividade pela qual a vida é sustentada, por ser a mais privada das atividades, tendo sido, até mesmo, costume torná-lo como algo que se passa dentro do domínio doméstico; o seu agente é o animal laborans. Ao tentar suprir as necessidades elementares da vida, o animal laborans não apresenta condições próprias de se manter, o que faz com que o Estado intervenha em sua vida. Isso nos leva a crer que os 
trabalhadores, em geral, gradualmente, são confundidos com o animal laborans, aprisionados às necessidades básicas da vida.

Até certo momento da história, as IES católicas vinham desenvolvendo uma "gestão doméstica", sem se deixar contaminar pela macroeconomia do sistema neoliberal. 0 mercado global aglutinou as instituições educacionais em nome da macroeconomia para poder sobreviver. Com isso, velhas práticas burocráticas de gestão cederam lugar para outras mais flexíveis. Nesse sentido, Sennet (2009, p. 23) afirma que "as empresas buscaram eliminar camadas burocráticas, tornando-se organizações mais planas e flexíveis. Em vez das organizações tipo pirâmides, a administração quer agora pensar nas organizações em redes." Sob esse ponto de vista, o modelo de governança corporativa da União de Educação Corporativa (2016) está enraizado em serviços compartilhados e em rede, mas é exacerbadamente centralizado.

Para Giroux (2010, p. 27, grifo do autor),

\begin{abstract}
em uma época em que a cultura de mercado coloniza agressivamente o cotidiano e em que as formas sociais, cada vez mais, perdem sua forma ou desaparecem por completo, o Ensino Superior parece representar uma reconfortante permanência, como um marco de lentas mudanças, em meio a uma paisagem de rápida dissolução das esferas públicas críticas.
\end{abstract}

A macroeconomia toma como referência o mercado educacional, ao examinar as formas de organização empresarial-educacional, cujos impactos variam na inovação tecnológica, nos níveis de motivação de cada colaborador, na lealdade à instituição e nas redes de comunicação entre os vários níveis hierárquicos.

De acordo com Audy (2017, p. 85), "a inovação emerge como o motor desse processo de transformação, levando a pesquisa à sociedade, atuando como fonte de resolução de problemas e abertura de novas possibilidades." Outro estudo igualmente interessante vem de Magaldi e Salibi Neto (2018), por trazerem a necessidade da adoção de um novo sistema de pensamento que se adeque aos desafios da atualidade, em nosso caso, os desafios da gestão universitária católica.

De notar que nem sempre a inovação acompanha o desenvolvimento humano; ela tem sido utilizada muito mais para o desenvolvimento econômico dos países. Investe-se em inovação para responder às leis do mercado. Nesse contexto, Rossato (2011, p. 186) afirma que se obrigou a universidade a uma abertura ao mundo do capital e pela "perspectiva de que o mundo é um grande mercado, a educação passa a ser vista como uma moeda de troca, e um produto a ser disputado no vasto universo dos negócios. A mercantilização da educação leva ao neocolonialismo no ensino superior." 
Seguindo esse pensamento, pesquisadores do Banco Mundial também manifestam a relação que há entre a mão de obra e o crescimento econômico. Para Ferreyra et al. (2018, p. 1), "com o ensino superior, o país forma mão de obra qualificada e fomenta a capacidade de gerar conhecimentos e inovação - que, por sua vez, aumentam a produtividade e o crescimento econômico." Sob o ponto de vista desses pesquisadores, a prosperidade da sociedade ocorre via produtividade econômica. 0 que, de alguma forma, corrobora com a lógica de gestão empresarial-educacional, a qual Catini (2019) faz duras críticas, por entender que esse tipo de gestão leva a estabelecer metas, avaliação sistemática do rendimento acadêmico, dando responsabilidade ao indivíduo pelo seu sucesso ou fracasso.

Contrariamente a esse pensamento mercadológico, a missão da mantenedora União de Educação Corporativa (2016) explicita em "servir à humanidade e à lgreja, por meio da Educação e da ação social, com o propósito de alcançar o desenvolvimento integral da pessoa humana e a transformação da sociedade, para uma cidadania engajada, responsável e comprometida com os valores éticos e cristãos." Isso quer dizer que o marco legal institucional prega uma gestão compartilhada no exercício do poder com os outros, ajudando a universidade a alcançar os objetivos institucionais compartilhados.

Como se vê, a formação de cidadãos é a opção nessa lnstituição e não pode ser consolidada pela lógica que Montaño (2003) chamou de "nova consciência social" empresarial ou de "empresa cidadã", em que se busca disfarçar, por meio da modalidade do capital, as relações lucrativas que encobrem o legítimo e crescente interesse pelo lucro. Ainda sobre a lucratividade do mercado educacional e uma crítica à ciência construída na universidade, Chaui (2003, p. 8) chama à atenção de que

\footnotetext{
A ciência deixou de ser teoria com aplicação prática e tornou-se um componente do próprio capital. Donde as novas formas de financiamento das pesquisas, a submissão delas às exigências do próprio capital e a transformação da universidade numa organização ou numa entidade operacional.
}

Longe de ser, essa descrição, um modelo de universidade que leve em conta a perenidade da educabilidade do ser humano em vista de valores mais elevados e nobres.

As estruturas universitárias modernas são consequências da história das nações onde estão inseridas e onde foram produzidas. Nesse sentido, Castanho (2002) afirma que o modelo de universidade brasileira foi influenciado pelos modelos europeus e norteamericanos. Embora para Rossato (2011, p. 204), "a universidade brasileira não gerou um modelo próprio e as transformações recentes indicam caminhar para a pluralidade, algumas delas quebrando os paradigmas dominantes outras - a grande maioria - introduzindo 
pequenas reformas permanecem na estrutura tradicional." Bem verdade que as nações europeias criaram as universidades como subprodutos de um desenvolvimento social global. Em importante texto de Cunha (2007, p. 151), sobre ensino superior brasileiro, destaca-se "a privatização e a fragmentação institucional" como características nesse campo. Criando-se a formação dos oligopólios, em que grandes empresas privadas controlam a maioria da oferta educacional, por meio de fusões e compras de instituições pequenas e da abertura do capital nas bolsas de valores. Concomitante a isso, há o desmonte da universidade pública por parte do Estado, o que Chaves (2010, p. 496) identificou como "práticas instrumentais e utilitaristas, distanciando-se da reflexão crítica e da educação como possibilidade emancipadora."

Dessa maneira, as instituições sociais mantêm as estruturas em que estão inseridas, mas também as altera. Promove-se uma ação renovadora em que as universidades são analisadas como motores de aceleração do desenvolvimento nacional como resposta aos apelos do mercado capitalista. Com isso, crises estruturais e tensões institucionais, internas e externas, são estabelecidas como divergências de ritmos entre a sociedade e a universidade. Sabemos, além disso, que a gênese da universidade brasileira teve influência dos modelos universitários francês, inglês, alemão e norte-americano, os quais influenciaram, a seu tempo, períodos nas gestões das $\mathbb{E E S}$ brasileiras.

Não é novidade que os modelos de administração universitária vêm sendo gradativamente gestados a partir de práticas de gestão empresarial. Os gestores acadêmicos passam a ser cobrados, em suas atribuições, a terem as melhores práticas incorporadas no cotidiano de sua gestão. São cobradas competências técnicas, resultados rápidos que coadunem com a lei do mercado, enxugamento dos quadros corporativos, serviços terceirizados, controles mais rígidos e focados em normas, "políticas" e regulamentos.

Não podemos esquecer que esse tipo de gestão na universidade se faz, muitas vezes, de forma segmentada, ao responder ao sistema que estratifica a educação e que a moldura em classes sociais. Acomodando as contradições sociais existentes, o que de certa forma contradiz a missão de uma instituição educacional católica.

Vale salientar que, dentro do Plano de Gestão da UCR, a sua missão é a de "transformar a pessoa e a sociedade por meio da produção e gestão do conhecimento, comprometida com os valores cristãos." (UNIVERSIDADE COMUNITÁRIA REGIONAL, 2018). A universidade de fato, nessa acepção, torna-se um dos poucos lugares onde as pessoas podem aprender como viver em comunidade interdependente e bem-sucedida, traduzindo o imenso valor social que ela encontra como método de atuação.

Uma comunidade que quer se abrir a viver coisas novas, com uma aproximação que se vincula na condição da reciprocidade de dar e receber. Essa relação é imediata e toca a totalidade dos seres que se encontram nela. Entendemos, como Buber (2012, p. 85), que a 
comunidade "abrange toda a vida, toda a existência natural do homem, não excluindo nada dela." Esse tipo de comunidade parece privilegiar a inteireza das relações humanas.

Esse tipo de comunidade também ratifica o pressuposto fundamental da União de Educação Corporativa (2017), quando ela assume ser, em sua identidade, uma instituição humanista e cristã, ao ser "fundamentada nos valores cristãos da existência humana, na valorização da vida em todas as suas formas, na dignidade da pessoa humana e na liberdade pessoal [...]" Esses princípios apontam para a identidade de uma universidade católica, na qual todos estão empenhados em se educar em vista do crescimento e do desenvolvimento de todas as pessoas.

\section{A IDENTIDADE DA UNIUERSIDADE CATÓLICA}

0 Concílio Ecumênico Vaticano II, iniciado com o Papa João XXIII, em 1962, e encerrado pelo Papa Paulo Vl, em 1965, definitivamente foi o Concílio que "abriu as portas" da lgreja para todo o mundo. Inspirado no desejo de ser resposta para o mundo moderno, apresentou um programa que se ocupou com os problemas concernentes à doutrina e com aspectos da prática da lgreja, com a finalidade de estar de acordo com os ensinamentos do Evangelho e que, ao mesmo tempo, tivesse o reflexo das atividades humanas.

0 progresso científico e tecnológico não foi acompanhado de igual desenvolvimento moral e ético. A lgreja diante disso, sentia-se com a necessidade de dar uma resposta mais eficaz aos sinais dos novos tempos. Para tanto, fazia-se necessária e urgente uma renovação da lgreja, para que se pudesse pôr o mundo moderno em contato com o Evangelho. Foi nesse contexto que a lgreja ofertou ao mundo a Declaração Gravissimum Educationis (CONCíLIO VATICANO II, 1978) sobre a Educação Cristã, a qual trata dos princípios fundamentais que a alicerçam.

Essa Declaração defende o direito à educação de qualidade, a criação de instituições católicas, o acesso de todos aos bens da cultura e do saber. Essa posição, sempre muito clara e firme, reflete, antes de tudo, a defesa da liberdade e a promoção da justiça para todos, uma vez que pessoas esclarecidas têm mais e melhores condições de participar da permanente busca da verdade, da construção do bem comum, da solidariedade e da paz.

0 direito do ser humano à educação, bem como potencializar a sua liberdade perante os demais pode ser visto como "caminho" contínuo para a autoformação e uma posição firme de que a pessoa é um ser de relação social. Sobre isso, o depoimento de Giroux (2010, p. 36) acerca da educação se torna emblemático para a nossa reflexão, pois para o referido autor 
A educação não se dá apenas quanto a questões de trabalho e economia, mas também quanto a questões de justiça, liberdade social, capacitação para uma atuação democrática, de ação e de mudança, bem como a questões de poder, exclusão e cidadania. A educação, no seu melhor, trata de como habilitar os alunos a encarar seriamente a forma como eles devem viver suas vidas, defender os ideais de uma sociedade justa e agir de acordo com a esperança de uma democracia forte.

Portanto, cremos que na passagem de condições menos humanas às condições mais humanas reside o novo sentido de educar. Há de se perseguir, sob essa ideia, um trabalho permanente tecido por aqueles que fazem a educação. 0 amor à alma e o fundamento da justiça são elementos importantes para a educação como caminho da paz, pois se torna um constante balizamento para a vida (FRANCISCO, 2018b).

João Paulo I| (1990), em sua Constituição Apostólica Ex Corde Ecclesiae, afirma que a missão de uma universidade católica "é a procura contínua da verdade, a concepção e a comunicação do saber para o bem da sociedade", um serviço que se liga à promoção da justiça social. Sobre a natureza de uma universidade católica, o sumo pontífice conduz ao pensamento de que "Art. $2 \S 1$ [...] é uma comunidade de estudiosos, representada por vários campos do saber humano. Ela se dedica à investigação, ao ensino e às várias formas de serviço compatíveis com a sua missão cultural." (JOÃO PAULO II, 1990).

Desde o seu princípio, comunidade é um termo caro para a lgreja Católica, uma vez que o modelo de comunidade é aquele que guia e aprimora a missão central da educação, de conhecer, de ensinar e de aprender em prol do bem comum. Nessa acepção, Juliatto (2007, p. 27) assegura que

\footnotetext{
Educar é, em essência, criar espaço para o conhecimento da realidade e para que a busca da verdade seja assumida por todos, mestres e alunos. A característica principal da comunidade que busca a verdade é a abertura para a descoberta e aceitação da realidade dos fatos e propriedade de ideias.
}

A educação e a formação devem permitir uma leitura crítica do mundo, um mundo inacabado, e isso implica a denúncia da realidade opressora, da realidade injusta e incompleta, consequentemente, de crítica transformadora e de anúncio de uma outra realidade. Poderíamos dizer que é o próprio anúncio do Evangelho, como essência de uma instituição católica, que busca a promoção humana. 0 anúncio é necessário como um momento de uma nova realidade a ser criada. Essa nova realidade do amanhã é a utopia. Vemos, portanto, pela 
Educação Superior, uma possibilidade de crescimento e potencialização dos seres humanos, tornando-os mais justos, melhores e mais amorosos.

A educação, nesse sentido, tem um papel extremamente relevante na perspectiva social e dos problemas hodiernos que a sociedade enfrenta. Dentro dessa perspectiva, "a universidade católica deve estudar os dificeis problemas contemporâneos e elaborar projetos de solução que concretizem os valores religiosos e éticos, próprios de uma visão cristã do homem." (CONGREGAÇÃO PARA A EDUCAÇÃO; PONTIF́́CIO CONSELHO PARA OS LEIGOS; PONTIFíCIO CONSELHO DA CULTURA, 1994).

0 impacto da economia neoliberal cria cenários de risco dos quais não temos experiências anteriores que nos orientem sobre o que fazer diante deles. As mesmas transformações técnico-científicas produzem rachaduras indeléveis nos modos de funcionamento das instituições clássicas, sobretudo nas de Educação. Sendo a universidade uma instituição social, seu desempenho precisa ser avaliado com relação à missão e à identidade. 0 retorno financeiro é consequência e não um fim em si mesmo, como o mercado aponta. Uma universidade tem objetivos sociais a perseguir, como função de formadora de cidadania, requer respeito e tolerância diante da diversidade de ideias e opiniões, em razão de sua função, igualmente, de crítica da própria sociedade.

A Conferência Nacional dos Bispos do Brasil (2019, p. 14) se manifestou sobre o entendimento de uma Universidade Católica como:

\footnotetext{
Um ambiente de cultura e saber. 0 seu tripé indissociável (ensino, pesquisa, extensão) e os seus atores (universitários, professores e colaboradores) constituem o rito e a alma dessa comunidade do conhecimento. Por sua tarefa de produção intelectual, busca analisar a realidade e oferecer resposta científica aos relevantes problemas da atualidade. A universidade é um verdadeiro laboratório da vida profissional.
}

0 alcance que uma educação de qualidade possui, seja por meio de educação formal, seja informal, é sempre um legado inestimável para seu portador. Nesse sentido, a Educação Superior gera nas pessoas atitudes que comprometerão, de forma positiva, a sociedade em geral. Ela se torna indispensável como instância intermediadora, estabelecendo vínculos entre as novas gerações e a cultura acumulada como herança; local privilegiado para a crítica do saber apropriado e de estimular as relações libertadoras.

Dessa forma, a liberdade é a categoria central da concepção educativa desde sua gênese, pois ela é o fim da educação. Sua finalidade reside em libertar a pessoa de qualquer realidade opressiva e de injustiça. É para isso que ela vem cumprir seu papel social, de promover a liberdade para transformar a pessoa e a sociedade. Essa libertação sempre 
terá o papel de transformar a realidade para melhorá-la, para torná-la mais humana, para permitir que homens e mulheres sejam reconhecidos como protagonistas da sua história e não como objetos (CONCÍLIO VATICANO II, 1978).

No Documento sinodal de Puebla (CONSELHO EPISCOPAL LATINO-AMERICANO, 2004, p. 335), os bispos latino-americanos pedem que a universidade católica procure se "sobressair pela honestidade científica, pelo compromisso com a verdade, pela preparação de profissionais competentes para o mundo do trabalho e pela pesquisa de soluções para os problemas mais angustiantes da América Latina." Para isso, é importante que no seio da comunidade universitária se promova uma cultura organizacional que privilegie laços estáveis e dinâmicos entre as pessoas, respeitando-se as diferenças ideológicas para se chegar ao núcleo cultural da comunidade. Consequentemente, deve haver a alegria da busca da verdade (FRANCISCO, 2018a). Para isso, a mantenedora, no papel de sentinela e provedora, ajuda a universidade católica a garantir sua função humanitária de formar pessoas no mais alto grau de liberdade.

Como disse Zamagni (2013, p. 8-9), "na situação presente, as universidades católicas têm a missão de resgatar a própria ideia de universidade", o que historicamente as tornaram perenes, segundo o autor. As universidades católicas de hoje devem "estabelecer uma aliança com a sociedade civil, mas com a sociedade civil organizada", e criar um modelo de educação que leve o estudante a "entrar na totalidade da realidade". Isso se deve à abertura de pensamento, a novas perspectivas de ensinar e de aprender. A universidade católica deve se inserir no mundo e buscar sempre a verdade. Diante dos desafios que a sociedade nos apresenta, não devemos ter medo de enfrentá-los. Por fim, a universidade deve ser o lócus do pensamento diverso, da circulação das múltiplas ideias, das fontes inesgotáveis de sabedoria.

\section{ALGUMAS CONSIDERAÇÕES FINAIS}

A educação é essencial ao desenvolvimento humano, visto que o processo educativo que fundamenta a formação humana, compreendida como formação integral do ser humano, visa ao direito de as pessoas viverem em comunidade. Para mudar a visão burocrática-tecnicista de gestão da universidade buscamos analisar, neste ensaio, as formas de gerir essa instituição e novos paradigmas de gestão, que nem sempre coadunam com a natureza de uma universidade católica.

Talvez não seja preciso reestruturar completamente a gestão universitária, abandonando as velhas práticas de gestão, mas conciliá-la com traços de uma gestão 
profissional que qualifique os processos e as pessoas. Exige-se, em nosso ponto de vista, que se pense de outra forma e se adotem comportamentos diferentes baseados em paradigmas mais humanistas e menos mercadológicos.

Nesse sentido, a alteridade passa a ser um imperativo ético da educação, uma vez que sustenta a convivência entre os desiguais. Compreendemos que o ato de educar não é restrito à escolarização e à transmissão de conteúdos, mas entendido como prática social que leva em consideração o cuidado com o outro e eleva o espírito humano a uma categoria de excelência.

0 cumprimento dos direitos fundamentais, pela educação, possibilita aos seus destinatários terem mais oportunidades perante os desafios das desigualdades sociais que o Brasil ainda enfrenta. Com isso, o gestor acadêmico busca cumprir, pela sua missão, que a educação é um dos direitos fundamentais para se qualificar a vida em nosso Planeta. Ao gerir processos, cumprir diretrizes, planos e políticas, esse gestor coloca sob a sua responsabilidade o foco na gestão do conhecimento com muito profissionalismo. E, em se tratando de universidade confessional, a sua responsabilidade é maior ainda, pois tem o compromisso primordial com a verdade e com a justiça social.

Dentro dessa perspectiva, é necessário garantir uma gestão acadêmica baseada em valores éticos, que comprometa as futuras gerações a terem mais qualidade de vida. Além disso, deve-se combater a concentração de renda em nosso País, o que faz as injustiças sociais e demais mazelas a ela atribuídas se acirrarem, pois isso passa a ser determinante para se ter igualdade social. Acreditamos que, dessa maneira, os ambientes educacionais universitários, em especial os católicos, devem privilegiar o senso coletivo e comunitário para surtir efeitos qualitativos em termos de justiça social.

A compreensão que temos de gestão, em sua forma mais colegiada e pelo primado ao princípio da transparência, não é o que ocorre na realidade em muitas instituições universitárias. 0 serviço que muitos gestores fazem para avançar nas mudanças necessárias para se adequar ao mercado neoliberal cria um clima organizacional insatisfatório para a comunidade acadêmica, o que impossibilita que essa instituição persiga indicadores de qualidade, do ponto de vista humano. Dentro dessa linha, se formos guiados por modelos teóricos de gestão inspirados, exclusivamente, nas ciências exatas, como o positivismo, o pragmatismo e o utilitarismo, sem que as ciências sociais nos balizem, poderemos cair na barbárie administrativa.

Acreditamos que a finalidade de uma IES católica não seja exclusivamente econômica e financeira, embora sejam aspectos importantes para mantê-la. A finalidade de uma instituição católica é, primordialmente, a promoção humana e social, à luz de valores genuinamente cristãos. Relevante ressaltar, desse ponto de vista, que o trabalho da Educação 
Superior não pode ser considerado unicamente sob o ângulo da produção e dos resultados, mas igualmente sob o ângulo do sentido da atividade, da subjetividade e da vivência, que são variáveis tão importantes quanto a produção e a rentabilidade.

Na esteira do refletido neste estudo, não queremos negar que as novas formas de fazer gestão são importantes, pois modelos se configuram a cada momento. Bem verdade que o novo cenário mercadológico de educação exige das instituições estruturas organizacionais mais leves e "ajustadas" ao mundo corporativo. 0 que não queremos esquecer, como apontamento de uma instituição confessional católica, é de sua finalidade em ser "uma comunidade acadêmica que, de modo rigoroso e crítico, contribui para a defesa e desenvolvimento da dignidade humana e para a herança cultural mediante a investigação, o ensino e os diversos serviços prestados às comunidades locais, nacionais e internacionais." (JOÃO PAULO II, 1990). Com isso, abre-se à flexibilidade do universo acadêmico para assumir novas posturas diante da realidade, como uma gestão humanizadora.

Por fim, a universidade tem um papel preponderante em escolher qual a marca relacional que ela quer optar para a sua comunidade. Ao qualificar e aprimorar o conhecimento, a universidade devolve à sociedade a esperança de um futuro melhor, com práticas embasadas em bons conhecimentos, abrindo-se aos diversos discursos e propiciando relações autênticas entre as pessoas. Possibilita, ainda, a geração de novos conhecimentos, rompendo-se a lógica da padronização, da ideologia totalitária da sociedade da informação e da certificação. As pessoas que vivenciam relações dialógicas, nesse tipo de comunidade universitária, permitem informações novas nos processos de conhecimentos. Nesse cenário, o papel do gestor profissional, como maestro da orquestra acadêmica, é fundamental para o acerto do ritmo.

\section{REFERÊNCIAS}

ARENDT, H. A condição humana. Tradução: Roberto Raposo. 5. ed. rev. Rio de Janeiro: Forense Universitária, 1991.

AUDY, J. A inovação, o desenvolvimento e o papel da Universidade. Estudos Avançados, São Paulo, v. 31, n. 90, p. 75-87, 2017. Disponivel em: http://www.revistas.usp.br/eav/article/view/137885/133471. Acesso em: 2 set. 2019.

BUBER, M. Sobre comunidade. 2. reimp. Tradução: Newton Aquiles Von Zuben. São Paulo: Perspectiva, 2012. (Debates, 203).

CARVALHO, C. H. A. A mercantilização da Educação Superior brasileira e as estratégias de mercado das instituições lucrativas. Revista Brasileira de Educação, Rio de Janeiro, v. 18, n. 54, p. 761-801, jul./ set. 2013. Disponível em: http://www.scielo.br/pdf/rbedu/v18n54/13.pdf. Acesso em: 16 jul. 2019. 
CASTANHO, S. Da universidade modelo aos modelos de universidade. Quaestio - Revista de Estudos de Educação, Sorocaba, ano 4, n. 1, p. 27-43, maio 2002. Disponível em: http://periodicos.uniso.br/ojs/ index.php/quaestio/article/view/1394/1377. Acesso em: 3 ago. 2019.

CASTEL, R. As metamorfoses da questão social: uma crônica do salário. Tradução: Iraci D. Poleti. 9. ed. Petrópolis, RJ: Vozes, 2010.

CATINI, C. Educação e empreendedorismo da barbárie. In: CÁSSIO, F. (org.). Educação contra a barbárie: por escolas democráticas e pela liberdade de ensinar. São Paulo: Boitempo, 2019. p. 33-39. (Tinta Vermelha).

CHAUl, M. A universidade pública sob nova perspectiva. Revista Brasileira de Educação, Rio de Janeiro, n. 24, p. 5-15, set./dez. 2003. Disponivel em: http://www.scielo.br/scielo.php?script=sci_ arttext\&pid=S1413-24782003000300002\&lng=en\&nrm=iso. Acesso em: 16 ago. 2019.

CHAVES, V. L. J. Expansão da privatização/mercantilização do ensino superior Brasileiro: a formação dos oligopólios. Educação \& Sociedade, Campinas, SP, v. 31, n. 111, p. 481-500, abr./jun. 2010. Disponível em: http://www.scielo.br/scielo.php?script=sci_arttext\&pid=S0101-73302010000200010\&lng=en\&nrm=iso. Acesso em: 13 abr. 2020.

CONCÍLIO VATICANO II. Declaração Gravissimum Educationis sobre a educação cristã. In: Compêndio do Vaticano II: Constituições, Decretos, Declarações. 12. ed. Petrópolis, RJ: Vozes, 1978.

CONFEREANCIA NACIONAL DOS BISPOS DO BRASIL. Setor Universidades da lgreja no Brasil: identidade e missão. Brasília, DF: CNBB, 2019. (Estudos da CNBB, 112).

CONGREGAÇÃO PARA A EDUCAÇÃO; PONTIFÍCIO CONSELHO PARA OS LEIGOS; PONTIFÍCIO CONSELHO DA CULTURA. Presença da lgreja na Universidade e a cultura universitária. 1994. Disponivel em: http://www. vatican.va/roman_curia/pontifical_councils/cultr/documents/rc_pc_cultr_doc_22051994_presence_po.html. Acesso em: 18 set. 2019.

CONSELHO EPISCOPAL LATINO-AMERICANO. Conclusões da Conferência de Puebla - 1979: evangelização no presente e no futuro da América Latina. 13. ed. São Paulo: Paulinas, 2004. (Sal da Terra).

CRESWELL, J. W. Projeto de Pesquisa: métodos qualitativo, quantitativo e misto. Tradução: Magda França Lopes. 3. ed. Porto Alegre: Artmed, 2016. (Métodos de Pesquisa).

CUNHA, L. A. Ensino Superior e Universidade no Brasil. In: LOPES, E. M. T.; FARIA FLLHO, L. M.; VEIGA, C. G. (org.). 500 anos de Educação no Brasil. 3. ed. Belo Horizonte: Autêntica, 2007. p. 171-204.

DEJOURS, C. A banalização da injustiça social. Tradução: Luís Alberto Monjardim. 6. ed. Rio de Janeiro: FVG, 2005.

DIAS, R. Sociologia \& Administração. 2. ed. rev. ampl. Campinas: Alínea, 2001. 
DONKIN, R. Sangue, suor e lágrimas: a evolução do trabalho. Tradução: Roger Maioli dos Santos. São Paulo: M. Books do Brasil, 2003.

DRUCKER, P. F. 0 gestor eficaz. Tradução: Jorge Fortes. Rio de Janeiro: LTC, 2017.

FAYOL, J. H. Administração industrial e geral: previsão, organização, comando, coordenação e controle. Tradução: Irene de Bojano, Mário de Souza. 10. ed. São Paulo: Atlas, 1990.

FERREYRA, M. M. et al. Em uma encruzilhada: Ensino Superior na América Latina e Caribe - Panorama. Brasilia, DF: Grupo Banco Mundial, 2018. Disponivel em: https://openknowledge.worldbank.org/bitstream/handle/10986/26489/211014ovPT.pdf? sequence=8. Acesso em: 4 set. 2019.

FLICK, U. Introdução à pesquisa qualitativa. Tradução: Joice Elias Costa. 3. ed. Porto Alegre: Artmed, 2009. (Métodos de Pesquisa).

FRANCISCO. Constituição Apostólica Veritatis Gaudium: sobre as Universidades e as Faculdades Eclesiásticas. São Paulo: Paulinas, 2018a. (Voz do Papa, 205).

FRANCISCO. Discurso do Papa Francisco aos membros da Fundação Gravissimum Educationis. 25 jun. 2018b. Disponivel em: http://w2.vatican.va/content/francesco/pt/speeches/2018/june/documents/ papa-francesco_20180625_gravissimum-educationis.html. Acesso em: 19 set. 2019.

GAULEJAC, V. Gestão como doença social: ideologia, poder gerencialista e fragmentação social. Tradução: Ivo Stomiolo. 3. ed. Aparecida, SP: Ideias \& Letras, 2007. (Management, 4).

GIROUX, H. Ensino superior, para quê? Tradução: Elisabeth Seraphim Prosser. Educar em Revista Curitiba, n. 37, p. 25-38, maio/ago. 2010. Disponivel em: https://revistas.ufpr.br/educar/article/ view/18519/12055. Acesso em: 3 set. 2019.

ISMAIL, S.; MALONE, M. S.; GEEST, Y. Organizações Exponenciais. Por que elas são 10 vezes melhores, mais rápidas e mais baratas que a sua (e o que fazer a respeito). Tradução: Gerson Yamagami. São Paulo: HSM, 2015.

JEZINE, E. et al. Globalização e políticas para a Educação Superior no Brasil: as lutas sociais e a lógica mercantilista. In: TEODORO, A. (org.). A Educação Superior no espaço ibero-americano: do elitismo à transnacionalização. Lisboa: Edições Universitárias Lusófonas, 2010. p. 275-309. (Ciências da Educação, Série Debates e Perspectivas).

JOÃO PAULO II. Constituição Apostólica Ex Corde Ecclesiae. 1990. Disponível em: http://w2.vatican.va/ content/john-paul-ii/pt/apost_constitutions/documents/hf_. Acesso em: 17 set. 2019.

JULIATTO, C. I. Parceiros educadores: estudantes, professores, colaboradores e dirigentes. Curitiba: Champagnat, 2007. 
LAVAL, C. A escola não é uma empresa: o neoliberalismo em ataque ao ensino público. Tradução de Mariana Echalar. São Paulo: Boitempo, 2019.

LOPES, F. D.; BALDI, M. Redes como perspectiva de análise e como estrutura de governança: uma análise das diferentes contribuições. Revista de Administração Pública - FGV, Rio de Janeiro, v. 43, n. 5, p. 1007-1035, set./out. 2009. Disponivel em: http://bibliotecadigital.fgv.br/ojs/index.php/rap/article/ view/6720/5303. Acesso em: 16 ago. 2019.

MAGALDI, S.; SALIBI NETO, J. Gestão do amanhã: tudo o que você precisa saber sobre gestão, inovação e liderança para vencer na $4^{a}$ revolução industrial. São Paulo: Gente, 2018.

MARCONI, M. A.; LAKATOS, E. M. Metodologia do trabalho científico: procedimentos básicos, pesquisa bibliográfica, projeto e relatório, publicações e trabalhos científicos. 7. ed. 8. reimp. São Paulo: Atlas, 2013.

MINAYO, M. C. S. 0 desafio do conhecimento: pesquisa qualitativa em saúde. 12. ed. São Paulo: Hucitec, 2010. (Saúde em Debate, 46).

MONTAÑO, C. Terceiro setor e questão social: crítica ao padrão emergente de intervenção social. 2. ed. São Paulo: Cortez, 2003.

MORGAN, G. Imagens da organização. Tradução: Geni G. Goldschmidt. 2. ed. São Paulo: Atlas, 2006. (Edição Executiva).

RICHARDSON, R. J. Pesquisa social: métodos e técnicas. Colaboração de Dietmar Klaus Pfeiffer. 4. ed. rev. ampl. São Paulo: Atlas, 2017.

ROSSATO, R. A universidade brasileira face ao processo de Bolonha. In: PEREIRA, E. M. A.; ALMEIDA, M. L. P. (org.). Reforma universitária e a construção do espaço europeu de Educação Superior: análise de uma década do Processo de Bolonha. Campinas, SP: Mercado de Letras, 2011. p. 181-205.

SENNET, R. A corrosão do caráter: consequências pessoais do trabalho no novo capitalismo. Tradução: Marcos Santarrita. 14. ed. Rio de Janeiro: Record, 2009.

SEVERINO, A. J. Metodologia do trabalho científico. 23. ed. rev. atual. 5. reimp. São Paulo: Cortez, 2007.

SPRING, J. Como as corporações globais querem usar as escolas para moldar o homem para o mercado. Tradução: Ana Júlia Galvan. Campinas, SP: Vide Editorial, 2018.

TAYLOR, F. W. Princípios de administração científica. Tradução: Arlindo Vieira Ramos. 8. ed. 14. reimp. São Paulo: Atlas, 2009.

TEODORO, A. Educação, globalização e neoliberalismo: os novos modos de regulação transnacional das políticas de educação. Lisboa: Edições Universitárias Lusófonas, 2010. (Ciências da Educação, Série Argumentos). 
TEODORO, A.; SANTOS, E.; COSTA JUNIOR, R. University rankings: between market regulation and the diffusion of organizational models. The Brazilian case. Revista Lusófona de Educação, Lisboa, v. 41, n. 41, p. 175-191, 2018. Disponivel em: https://revistas.ulusofona.pt/index.php/rleducacao/article/view/6500. Acesso em: 9 abr. 2020.

UNIÃO DE EDUCAÇÃO CORPORATIVA. Governança corporativa da UEC. 2016.

UNIÃO DE EDUCAÇÃO CORPORATIVA. Estatuto da UEC. 2017.

UNIVERSIDADE COMUNITÁRIA REGIONAL. Plano de Gestão 2018-2025. 2018.

WAHLBRINCK, I. F.; PACHECO, L. M. D. Ética do cuidado e extensão universitária: da tomada de consciência à conscientização. Campinas, SP: Mercado de Letras, 2017.

ZAMAGNI, S. A identidade e a missão de uma universidade católica na atualidade. Tradução: Luis Marcos Sander. Cadernos IHU Ideias, São Leopoldo, RS, ano 11, n. 185, p. 3-19, 2013. Disponível em: http:// www.hu.unisinos.br/images/stories/cadernos/ideias/185cadernosihuideias_corrigido.pdf. Acesso em: 3 ago. 2019.

Endereços para correspondência: Lúcio Gomes Dantas - Universidade Católica de Brasília, Reitoria, Quadra QS 7, lote 1 - EPCT, Taguatinga, 71966-700, Brasilia, Distrito Federal, Brasil; lucio.dantas@ucb.br

Roteiro, Joaçaba, U. 45, p. 1-24, jan./dez. 2020 | e23255 |E-ISSN 2177-6059 